\title{
Effect of Tumor Necrosis Factor (TNF) on Lipid Metabolism in the Diabetic Rat Evidence That Inhibition of Adipose Tissue Lipoprotein Lipase Activity Is Not Required for TNF-Induced Hyperlipidemia
}

\author{
Kenneth R. Feingold, Mounzer Soued, llona Staprans, Laurence A. Gavin, Marilyn E. Donahue, Boa-Jun Huang, \\ Arthur H. Moser, Rocco Gulli, and Carl Grunfeld \\ Metabolism Section and Lipid Research Laboratory, Department of Medicine, University of California, San Francisco; \\ and the Veterans Administration Medical Center, San Francisco, California 94121
}

\begin{abstract}
Tumor necrosis factor (TNF) administration produces an increase in plasma triglycerides that may be due to inhibition of adipose lipoprotein lipase activity and/or a stimulation of hepatic lipogenesis. We now report that TNF administration to insulinopenic diabetic rats increases serum triglycerides $(2 \mathbf{~ h}$, 2.4-fold; 17 h, 4.3-fold). Adipose tissue lipoprotein lipase activity was markedly decreased in diabetic animals compared with controls and was not further inhibited by TNF. Incorporation of tritiated water into fatty acids in the liver was increased 45\% 1-2 h after TNF and 87\% at 16-17 h. These results indicate that the TNF-induced increase in circulating lipid levels can occur in the absence of a TNF-induced inhibition of adipose tissue lipoprotein lipase activity. Moreover, the clearance from the circulation of triglycerides in chylomicrons was similar in control and TNF-treated animals; these results provide further evidence that the removal of triglyceride-rich lipoproteins is not altered in the TNF-treated animals. Our data suggest that the TNF-induced stimulation of hepatic lipid synthesis may play an important role in the increase in serum triglycerides. In addition, TNF administration to diabetic animals leads to an elevation in serum glucose levels (73\% at $17 \mathrm{~h}$ ) without a change in serum insulin levels. Thus, TNF stimulation of hepatic lipogenesis is independent of changes in insulin.
\end{abstract}

\section{Introduction}

Disturbances in intermediary metabolism occur in association with infections by microorganisms (1). Hyperlipidemia, primarily due to the accumulation of VLDL, is one such metabolic aberration $(2,3)$. Hyperlipidemia in models of infection has been observed in a wide variety of species including humans, monkeys, rabbits, dogs, and rats (2-10). Studies have shown that model infections result in both a decrease in the metabolism of circulating lipoproteins $(8,9)$ and an increase in hepatic lipid synthesis (10).

Data presented in part at the 48th Annual Meeting of the American Diabetic Association, New Orleans, LA, June 1988 (1988. Diabetes. 37:40A. (Abstr.)).

Address correspondence to Dr. Kenneth R. Feingold, Veterans Administration Medical Center, Metabolism Section (111F), 4150 Clement Street, San Francisco, CA 94121.

Received for publication 7 October 1987 and in revised form 8 November 1988.

J. Clin. Invest.

(c) The American Society for Clinical Investigation, Inc.

0021-9738/89/04/1116/06 \$2.00

Volume 83, April 1989, 1116-11.21
The response to infections involves many cell types and is mediated by cytokines (11-13). Beutler and Cerami have proposed that tumor necrosis factor (TNF) ${ }^{1}$ is responsible for the hyperlipidemia that occurs in association with infection (14). Previously we have demonstrated that the administration of purified TNF to intact rats results in an increase in plasma triglyceride levels (15). In our studies, $2 \mathrm{~h}$ after TNF administration plasma triglyceride concentrations were increased 2.2fold and remained elevated for at least $17 \mathrm{~h}$ (1.7-fold increase). Plasma cholesterol concentrations also increase in response to TNF administration.

Studies from several laboratories have demonstrated that TNF in vitro decreases the activity of lipoprotein lipase in cultured fat cells (16-18), an effect that is due to the decreased synthesis of the enzyme (17). Recent experiments have demonstrated that the administration of purified TNF to intact animals can decrease adipose tissue lipoprotein lipase activity (19). A decrease in adipose lipoprotein lipase activity could lead to a decreased clearance of triglyceride-rich lipoproteins, such as VLDL, from the circulation and thereby result in hyperlipidemia. Thus, the hyperlipidemia that accompanies infections could be mediated solely by a TNF-induced inhibition of adipose tissue lipoprotein lipase activity.

However, we have recently shown that TNF administration to intact animals stimulates lipid synthesis in the liver (15). The hepatic incorporation of tritiated water into fatty acids was increased 1.6-fold at $1-2 \mathrm{~h}$ after TNF administration, and the ability of TNF to stimulate hepatic fatty acid synthesis persisted for an extended period of time (1.3-fold increase at $16-17 \mathrm{~h}$ ). Moreover, we have also observed that hepatic cholesterol synthesis was increased in TNF-treated animals. Thus, TNF stimulates both hepatic fatty acid and cholesterol synthesis, and this central effect of TNF could contribute to the observed hyperlipidemia.

The purpose of the present study was to determine whether inhibition of adipose tissue lipoprotein lipase by TNF is a prerequisite for the induction of hyperlipidemia by TNF administration or whether stimulation of hepatic lipid synthesis by itself could produce hyperlipidemia in TNF-treated animals. To this end we have studied the effect of TNF administration on plasma lipid levels and hepatic lipid synthesis in the streptozotocin-induced diabetic rat. Insulinopenic diabetes mellitus is associated with a markedly decreased activity of adipose tissue lipoprotein lipase $(20,21)$; therefore, we reasoned that under such circumstances TNF would not result in a further diminution of lipoprotein lipase activity, allowing us to elucidate more clearly the role of hepatic synthesis. In addi-

1. Abbreviations used in this paper: TNF, tumor necrosis factor. 
tion, we also compared the clearance of chylomicrons from the circulation in control and TNF-treated animals to determine if the administration of TNF altered the clearance of a triglyceride-rich lipoprotein.

\section{Methods}

Materials. Tritiated water $(1 \mathrm{Ci} / \mathrm{g})$ was purchased from ICN Radiochemicals (Irvine, CA). 26-[ $\left[{ }^{14} \mathrm{C}\right]$ Cholesterol, 4-[ $\left[{ }^{14} \mathrm{C}\right]$ cholesterol, $\left[{ }^{14} \mathrm{C}\right]-$ oleic acid, $\left[{ }^{14} \mathrm{C}\right]$ triolein, and ${ }^{125} \mathrm{I}$-labeled receptor grade porcine insulin were purchased from New England Nuclear (Boston, MA). The TLC polygram Sil G plates were purchased from Brinkmann Instruments, Inc. (Westbury, NY). Ultrafluor scintillation fluid was purchased from National Diagnostics, Inc. (Somerville, NJ). Unlabeled rat insulin was obtained from Novo (Wilton, CT). Guinea pig anti-rat insulin serum was purchased from Linco (Eureka, MO). Human TNF-alpha with a specific activity of $5 \times 10^{7} \mathrm{U} / \mathrm{mg}$ produced by recombinant DNA technology was kindly provided by Dr. H. M. Shepard from Genentech, Inc. (San Francisco, CA). Ketodiastix were obtained from Ames Division, Miles Laboratories (Elkhart, IN).

Animal procedures. Male and female Sprague-Dawley rats $(\sim 200$ g) were purchased from Simonsen Animal Vendors (Gilroy, CA). The animals were maintained on a reversed 12 -h light cycle (3 a.m.-3 p.m. dark, 3 p.m.-3 a.m. light) and were fed Simonsen rat chow and water ad lib. In female rats diabetes was induced, as in previous studies (22), by injecting the animals intraperitoneally after an overnight fast with $40 \mathrm{mg} / \mathrm{kg}$ streptozotocin in a $1-\mathrm{M}$ sodium citrate buffer ( $\mathrm{pH} 4.5$ ). The urines of the animals administered streptozotocin were periodically analyzed with Ketodiastix and animals were eliminated from the study if they did not have at least $1 \%$ glucosuria at all times or if they were ketonuric.

The animals were injected via the tail vein with $25 \mu \mathrm{g}$ of TNF in 0.5 $\mathrm{ml}$ of $0.9 \%$ saline or saline alone $10-14 \mathrm{~d}$ after streptozotocin administration. This dose is approximately one-quarter that shown to produce tumor necrosis in vivo (23) and is the optimal dose for increasing hepatic lipid synthesis in nondiabetic animals (15). Because TNF administration induces anorexia (24) all animals were fasted after injection to control for the effects of nutrition status on lipid synthesis.

Lipogenesis. At the time indicated after TNF administration, the animals were injected intraperitoneally with tritiated water $(50 \mathrm{mCi}) .1$ $\mathrm{h}$ later the animals were killed and weighed and a blood specimen was obtained. The livers were removed and individually weighed, and the lipid was saponified by refluxing overnight in a solution of $45 \% \mathrm{KOH}$, water, and $70 \%$ ethyl alcohol (2:1:5). The flasks were cooled and internal standards of $\left[{ }^{14} \mathrm{C}\right]$ cholesterol and $\left[{ }^{14} \mathrm{C}\right]$ oleic acid were added before extracting the nonsaponifiable material three times with $25 \mathrm{ml}$ of petroleum ether. The petroleum ether extract was dried, dissolved in chloroform, and then applied to TLC plates. The plates were developed in ethyl acetate: benzene (1:5) and the bands corresponding to standards of cholesterol were cut from the plate and counted by liquid scintillation. The window settings of scintillation counter were adjusted so that $<0.2 \%$ of the tritium counts were recorded in the ${ }^{14} \mathrm{C}$ window and $\sim 10 \%$ of the ${ }^{14} \mathrm{C}$ counts in the tritium window. Calculations were corrected for spillover of ${ }^{3} \mathrm{H}$, spillover of ${ }^{14} \mathrm{C}$, background, and recovery of internal standard.

After acidifying the saponified material to $\mathrm{pH}<2$ with concentrated hydrochloric acid, the fatty acids were extracted three times with petroleum ether. The extract was dried, dissolved in chloroform, and an aliquot counted as described above. The specific activity of the tritiated water was determined individually for each animal by measuring the disintegrations/minute per milliliter of plasma at the end of the experiment and dividing by millimoles of water/milliliter plasma ( $52 \mathrm{mmol} / \mathrm{ml}$ plasma assuming that plasma is $93 \%$ water). The validity of our methodology for measuring lipid synthesis has been demonstrated in earlier publications $(22,25)$.

Serum chemistries. Serum triglyceride levels were measured using diagnostic kit No. 405 (Sigma Chemical Co., St. Louis, MO) after extraction with Dole's reagent. Serum cholesterol levels were measured by using diagnostic kit No. 351 (Sigma Chemical Co.). Serum glucose levels were determined using a glucose analyzer (Yellow Springs Instrument Co., Yellow Springs, $\mathrm{OH}$ ).

Serum insulin levels were determined using a double antibody technique. Guinea pig anti-rat insulin serum (Linco) was used as the first antibody. Unlabeled rat insulin (Novo) was used as a standard. The tracer was ${ }^{125}$ I-labeled receptor grade porcine insulin.

Adipose tissue lipoprotein lipase analysis. At the time indicated after TNF administration, animals were killed and the periovarian fat pads were removed. Lipolytic activity was determined by the method of Pykalisto et al. (26), as described previously (27). Briefly, the substrate, unlabeled triolein $(200 \mathrm{mg}), 4.0 \mu \mathrm{Ci}$ of $\left[{ }^{14} \mathrm{C}\right]$ triolein, and $3.0 \mathrm{mg}$ of lecithin were homogenized with $1.2 \mathrm{ml}$ of $10 \%$ fatty acid-free bovine albumin (pH 8.2), $0.5 \mathrm{ml}$ of normal plasma (LPL cofactor), and $6.2 \mathrm{ml}$ of $1.0 \mathrm{M}$ Tris-HCl buffer (pH 8.2) using a sonifier (model S-125; Branson Sonic Power Co., Danbury, CT) for 3 min (setting 3 and maximal tuning). An aliquot of the resultant emulsion $(0.2 \mathrm{ml})$ and 0.1 $\mathrm{ml}$ of the heparin-extracted medium of periovarian adipose tissue (adipose LPL) were incubated in a metabolic shaker at $37^{\circ} \mathrm{C}$ for 60 $\mathrm{min}$. The reaction was stopped by addition of $10 \mathrm{ml}$ of Dole's extraction mixture. Triglycerides (triolein) and fatty acids (oleic acid) were extracted from the incubation mixture by three washings with heptane. Subsequently, the oleic acid was separated from triolein by the standard sequential alkalinization-reacidification heptane extraction procedure. The final heptane phase was transferred to counting vials and evaporated under nitrogen. The generated $\left[{ }^{14} \mathrm{C}\right]$ oleic acid was measured on a Tri-Carb liquid scintillation spectrometer (model B2450; Packard Instrument Co., Inc., Downers Grove, IL). The standard consisted of $20-\mu \mathrm{l}$ of the substrate emulsion. This was extracted initially by $5.0 \mathrm{ml}$ of heptane in $2.5 \mathrm{ml}$ water and then by $2.5 \mathrm{ml}$ heptane. Both extracts were added to the counting vials, evaporated, and measured. 1 $\mathrm{U}$ of lipoprotein lipase activity is defined as equivalents of FFA/g of tissue per $h$.

Chylomicron clearance studies. The major mesenteric lymph duct was cannulated in male rats. After establishment of lymph flow, the animals were administered $50 \mu \mathrm{Ci}$ of $4-\left[{ }^{14} \mathrm{C}\right]$ cholesterol and $100 \mu \mathrm{Ci}$ of $\left[{ }^{3} \mathrm{H}\right]$ triolein in $2 \mathrm{ml}$ of a corn oil-milk emulsion. The lymphatic drainage was collected in iced tubes for $18 \mathrm{~h}$. Chylomicrons were isolated by layering $5 \mathrm{ml}$ of lymph under $0.15 \mathrm{M} \mathrm{NaCl}$ and centrifuging at $5 \times 10^{6}$ $\mathrm{g} / \mathrm{min}$ at $10^{\circ} \mathrm{C}$. Labeled chylomicrons ( $10 \mathrm{mg}$ of triglyceride) were injected via the tail vein into male rats to whom either $25 \mu \mathrm{g}$ TNF or saline was administered intramuscularly $1 \mathrm{~h}$ before study. Blood samples $(0.075 \mathrm{ml})$ from the tail vein were obtained at $2,4,6,8,10,12,14$, 16,18 , and $20 \mathrm{~min}$ after chylomicron administration. The blood samples were extracted with Dole's reagent and an aliquot of liver with chloroform-methanol (2:1). The lipid phase was counted as described above. The $t_{1 / 2}$ of disappearance from the circulation of both the $\left[{ }^{3} \mathrm{H}\right]-$ triglyceride and $\left[{ }^{14} \mathrm{C}\right]$ cholesterol associated with the chylomicrons was calculated by linear regression analysis using Sigma-Plot (Jandel Scientific, Sausolito, CA) on an IBM personal computer A.T.

Statistical differences were determined by using a two-tailed $t$ test.

\section{Results}

The quantity of food intake is an important variable affecting serum lipid and glucose levels and hepatic lipid synthesis. TNF administration leads to anorexia; therefore, to control the quantity of food intake in individual groups of animals, all animals were fasted after TNF or saline administration. This resulted in a decrease in the serum glucose, triglyceride, and cholesterol levels in the diabetic control animals fasted $17 \mathrm{~h}$ vs. $2 \mathrm{~h}$ (Figs. 1-3). Similarly, hepatic cholesterol and triglyceride synthesis were also decreased in the diabetic control animals fasted $17 \mathrm{~h}$ vs. $2 \mathrm{~h}$ (Figs. 5 and 6 ).

Serum glucose levels. The effect of TNF administration on serum glucose levels in diabetic animals is dependent on the time of measurement. $2 \mathrm{~h}$ after TNF treatment no significant 


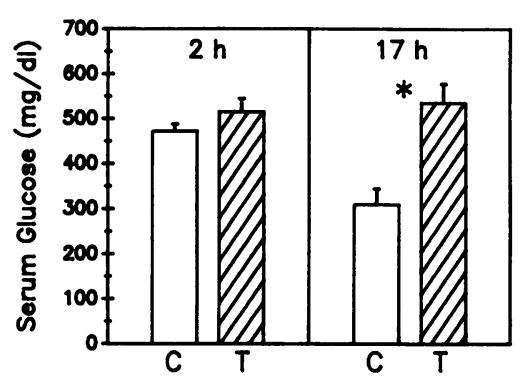

Figure 1. The effect of TNF on serum glucose levels. Values are mean \pm SE. Open bars are diabetic animals administered saline (control, $C ; n=11$ at $2 \mathrm{~h}$ and 15 at $17 \mathrm{~h}$ ) and hatched bars are diabetic animals administered TNF $(T ; n=11$ at $2 \mathrm{~h}$ and 15 at $17 \mathrm{~h})$. At 17 h $P<0.001$. alteration in serum glucose concentration was observed (Fig. 1). At $17 \mathrm{~h}$, though, the serum glucose levels were significantly higher in the animals administered TNF (73\% increase) compared with control animals (Fig. 1). Additionally, we observed that serum glucose concentrations were increased $70 \%$ as early as $4 \mathrm{~h}$ after TNF treatment. Despite the increase in serum glucose levels after TNF administration, ketones were not detectable in the urine. In the streptozotocin-induced diabetic rat serum insulin levels were very low $(1.36 \pm 0.23 \mathrm{ng} / \mathrm{ml})$ and did not change after TNF administration $(0.98 \pm 0.17 \mathrm{ng} / \mathrm{ml})$.

In nondiabetic animals we have also observed a slight increase in serum glucose levels in animals treated with TNF (nondiabetic animals [ $n=24] 17 \mathrm{~h}$ after $25 \mu \mathrm{g}$ TNF $137 \pm 4.6$ vs. nondiabetic animals $[n=25]$ administered saline $105 \pm 3.9$ $\mathrm{mg} / \mathrm{dl}, P<0.001$ ).

Serum lipid levels. The administration of TNF to diabetic animals resulted in a rapid and sustained increase in the serum triglyceride levels (Fig. 2). $2 \mathrm{~h}$ after TNF administration serum triglyceride levels were increased 2.4-fold, and at $17 \mathrm{~h}$ they were increased 4.3-fold as compared with matched diabetic animals that were administered saline. The pattern of the increase in serum triglyceride levels in response to TNF administration in diabetic animals was similar to our observations in control animals (15).

As shown in Fig. 3, serum cholesterol levels are significantly increased $17 \mathrm{~h}$ after TNF administration. At $2 \mathrm{~h}$ there was a tendency for the serum cholesterol to be increased in the TNF animals, but this difference did not reach statistical significance. In prior studies we also observed a significant increase in serum cholesterol levels in nondiabetic animals only after an extended period of time ( 7 and $17 \mathrm{~h}$ ) (15).

Adipose tissue lipoprotein lipase activity. Adipose tissue lipoprotein lipase activity was assayed in diabetic animals 90

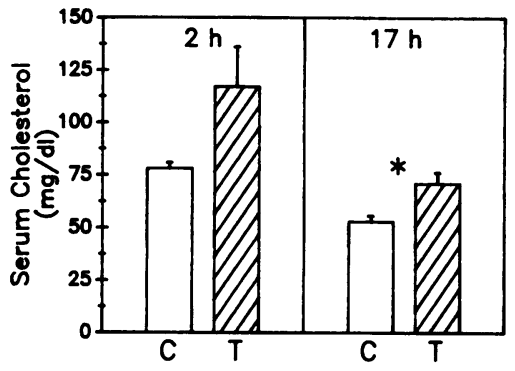

Figure 3. The effect of TNF on serum cholesterol levels. Values are mean \pm SE. Open bars are diabetic animals administered saline (control, $C ; n=11$ at $2 \mathrm{~h}$ and 15 at $17 \mathrm{~h}$ ) and hatched bars are diabetic animals administered TNF $(T ; n=11$ at $2 \mathrm{~h}$ and 15 at $17 \mathrm{~h}$ ). At 17 h $P<0.01$.

min and $17 \mathrm{~h}$ after TNF administration (Fig. 4). For comparison, lipoprotein lipase activity in nondiabetic animals is also presented. Adipose tissue lipoprotein lipase activity was considerably reduced in the insulinopenic diabetic rats. Most importantly, TNF administration did not further inhibit adipose tissue lipoprotein lipase activity in the diabetic rat at either early or late time points.

Lipid synthesis. The effect of TNF administration on the incorporation of tritiated water into fatty acids in the liver of diabetic animals is shown in Fig. 5. TNF treatment resulted in a rapid increase in hepatic fatty acid synthesis (1-2 h, increased $45 \%$ ) and this effect persisted for an extended period of time (16-17 h, increased 87\%). As noted earlier, the animals were fasted after saline or TNF administration, which accounts for the reduced fatty acid synthesis observed in the 17-h experiment. Thus, TNF stimulates hepatic fatty acid synthesis in diabetic animals in a manner similar to that which we observed in control animals (15).

The effect of TNF administration on the incorporation of tritiated water into cholesterol in the liver of diabetic animals is shown in Fig. 6. Similar to our previous observations in control animals, TNF administration to diabetic animals significantly increased hepatic cholesterol synthesis only after an extended period of time ( $79 \%$ increase at $16-17 \mathrm{~h})$. At earlier time periods TNF treatment had no significant effect on cholesterol synthesis in the liver of diabetic animals.

Previous studies by our and other laboratories have demonstrated that small intestinal cholesterol synthesis is increased in diabetic animals $(22,28)$; therefore, we quantitated lipid synthesis in the small intestine of diabetic animals 16-17 h after TNF administration. TNF administration did not affect

Figure 2. The effect of TNF on serum triglyceride levels. Values are mean $\pm S E$. Open bars are diabetic animals administered saline (control, $C ; n=11$ at $2 \mathrm{~h}$ and 15 at $17 \mathrm{~h}$ ) and hatched bars are diabetic animals administered TNF $(T ; n=11$ at $2 \mathrm{~h}$ and 15 at $17 \mathrm{~h}$ ). At $2 \mathrm{~h} P<0.05$ and at 17 h $P<0.001$.

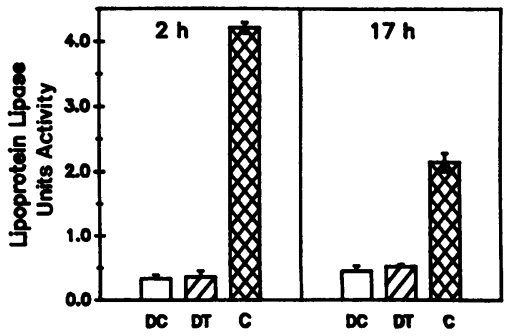

Figure 4. The effect of TNF on adipose tissue lipoprotein lipase activity. Values are mean \pm SE. Open bars are diabetic animals administered saline ( $D C$; $n=6$ at $2 \mathrm{~h}$ and 5 at 17 h), hatched bars are diabetic animals administered TNF $(D T ; n=6$ at $2 \mathrm{~h}$ and 5 at $17 \mathrm{~h}$ ), and double hatched bars are nondiabetic control animals $(C ; n$ $=5$ at both time points). 


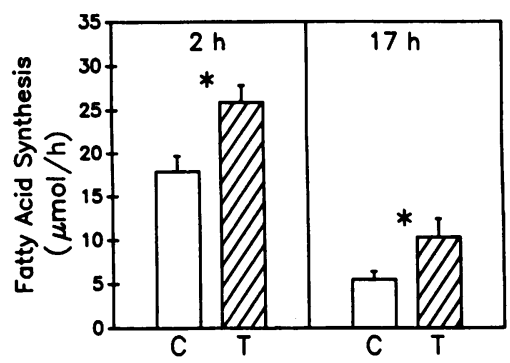

Figure 5. Effect of TNF on hepatic fatty acid synthesis. Values are mean $\pm \mathrm{SE}$ expressed as $\mu \mathrm{mol} / \mathrm{h}$ per total organ. At 1 or $16 \mathrm{~h}$ after the administration of TNF or saline the animals were injected with 50 mCi i.p. of tritiated water. $1 \mathrm{~h}$ later the animals were killed and the livers were removed, weighed, and saponified in a $\mathrm{KOH}$-ethanol solution. The incorporation of tritiated water into fatty acids was determined after petroleum ether extraction. Open bars are diabetics administered saline $(C ; n=5$ at $2 \mathrm{~h}$ and 10 at $17 \mathrm{~h}$ ) and hatched bars are diabetics administered TNF ( $T ; n=5$ at $2 \mathrm{~h}$ and 10 at $17 \mathrm{~h}$ ). At $2 \mathrm{~h} P<0.02$ and at $17 \mathrm{~h} P<0.05$.

either the incorporation of tritiated water into fatty acids or cholesterol in the small intestine of diabetic animals (fatty acids: diabetic $(n=5), 32.2 \pm 3.2$ vs. diabetic plus TNF $(n=5)$, $37.2 \pm 2.6 \mu \mathrm{mol}$ tritiated water incorporated per $\mathrm{h}$ NS; cholesterol: diabetic, $10.3 \pm 1.4$ vs. diabetic plus TNF, $8.6 \pm 0.6 \mu \mathrm{mol}$ tritiated water incorporated per h NS). These results are similar to previous results in control animals where we observed that the stimulation of lipogenesis by TNF was specifically localized to the liver (15).

Chylomicron clearance. Table I presents the $t_{1 / 2}$ of disappearance from the circulation of chylomicrons labeled with $\left[{ }^{3} \mathrm{H}\right]$ triglyceride and $\left[{ }^{14} \mathrm{C}\right]$ cholesterol in normal animals and normal animals administered TNF 60 min before study. In normal rats the $t_{1 / 2}$ of clearance of chylomicrons labeled with triglycerides is $3.23 \pm 0.22 \mathrm{~min}$ and the $t_{1 / 2}$ of clearance of chylomicrons labeled with cholesterol is $5.66 \pm 0.43 \mathrm{~min}$. These results are similar to previous observations in this and other laboratories (29-31). In TNF-treated animals the $t_{1 / 2}$ of clearance of the labeled chylomicrons is very similar to that observed in the control animals ( $t_{1 / 2}$ for triglycerides, 3.09 \pm 0.27 $\mathrm{min} ; t_{1 / 2}$ for cholesterol, $\left.5.50 \pm 0.35 \mathrm{~min}\right)$. The quantity of labeled triglycerides and cholesterol localized in the liver at 20 min after the administration of labeled chylomicrons was similar in the control and TNF-treated animals (triglyceride: control, $18.9 \pm 2.10 \%$, TNF, $16.7 \pm 1.71 \%$; cholesterol: control, $80.9 \pm 1.44 \%$, TNF, $78.7 \pm 4.34 \%$ of the administered label). In these experiments TNF was administered intramuscularly to

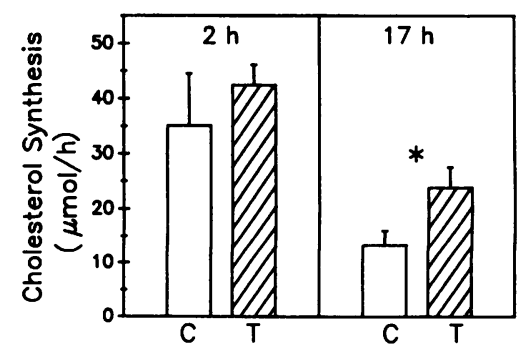

Figure 6. The effect of TNF on hepatic cholesterol synthesis. Values are mean \pm SE expressed as $\mu \mathrm{mol} / \mathrm{h}$ per total organ. At 1 or $16 \mathrm{~h}$ after the administration of TNF or saline the animals were injected with $50 \mathrm{mCi}$ i.p. of tritiated water. $1 \mathrm{~h}$ later

the animals were killed and the livers were removed, weighed, and saponified in a $\mathrm{KOH}$-ethanol solution. The incorporation of tritiated water into cholesterol was determined after petroleum ether extraction. Open bars are diabetics administered saline $(C ; n=5$ at $2 \mathrm{~h}$ and 10 at $17 \mathrm{~h}$ ) and hatched bars are diabetics administered TNF $(T ; n=$ 5 at $2 \mathrm{~h}$ and 10 at $17 \mathrm{~h}$ ). At $17 \mathrm{~h} P<0.05$.
Table I. The $t_{1 / 2}$ of Disappearance of Chylomicrons from the Circulation

\begin{tabular}{lcc}
\hline & Triglyceride label & Cholesterol label \\
\hline & $\min$ & $\min$ \\
Control $(n=9)$ & $3.23 \pm 0.22$ & $5.66 \pm 0.43$ \\
$\operatorname{TNF}(n=7)$ & $3.09 \pm 0.27$ & $5.50 \pm 0.35$ \\
& NS & NS
\end{tabular}

The mesenteric lymph from rats administered $4-\left[{ }^{14} \mathrm{C}\right]$ cholesterol and $\left[{ }^{3} \mathrm{H}\right]$ triolein was collected and the chylomicrons isolated by centrifugation. The labeled chylomicrons (10 mg of triglyceride) were injected intravenously into male rats administered $25 \mu \mathrm{g}$ i.m. TNF or saline $1 \mathrm{~h}$ before study. Blood samples were obtained every $2 \mathrm{~min}$ for $20 \mathrm{~min}$, extracted with Dole's reagent, and the lipid phase counted by liquid scintillation. The $t_{1 / 2}$ of disappearance from the circulation of both the $\left[{ }^{3} \mathrm{H}\right]$ triglyceride and $\left[{ }^{14} \mathrm{C}\right]$ cholesterol associated with the chylomicrons was calculated as described in Methods.

allow performance of chylomicron clearance using the tail vein. In parallel experiments TNF was shown to increase serum triglycerides $80 \mathrm{~min}$ after administration of $25 \mu \mathrm{g}$ i.m. (control, $48 \pm 2.1 \mathrm{mg} / \mathrm{dl}$; TNF, $66 \pm 3.1 \mathrm{mg} / \mathrm{dl}, P<0.01$ ). These results demonstrate that TNF treatment does not effect the clearance of a triglyceride-rich lipoprotein under conditions that produce a rise in serum triglycerides.

\section{Discussion}

The administration of TNF to intact animals leads to hyperlipidemia. There are two known mechanisms by which an increase in serum lipids could occur after TNF treatment. First, the ability of TNF to reduce adipose tissue lipoprotein lipase activity in cultured fat cells is well documented (16-18). A decrease in adipose tissue lipoprotein lipase activity could lead to a decreased clearance from the circulation of triglyceriderich lipoproteins and thereby result in hypertriglyceridemia. Second, recent studies by this laboratory have demonstrated that TNF administration to intact animals stimulates hepatic lipid synthesis (15) which could lead to an increased hepatic lipoprotein secretion, thereby resulting in hyperlipidemia. The relative importance of these two mechanisms in causing the hyperlipidemia induced by TNF administration is unknown.

In the present study we determined the effect of TNF administration on circulating lipid levels and hepatic lipid synthesis in streptozotocin-induced insulinopenic diabetic rats. The presence of insulin deficiency is well known to decrease markedly the activity of adipose tissue lipoprotein lipase (20, $21)$. In the present experiments we observed that adipose tissue lipoprotein lipase activity in the diabetic rats was $<20 \%$ of that seen in control animals. Most importantly, the administration of TNF to diabetic animals did not result in a further decrease in adipose tissue lipoprotein lipase activity. The above finding is in contrast to the findings in nondiabetic rats where decreases in adipose tissue lipoprotein lipase activity have been observed several hours after TNF administration (19). Thus, in insulinopenic diabetic animals adipose tissue lipoprotein lipase activity is markedly decreased and no further effect is seen in response to TNF administration.

TNF administration to diabetic animals results in a 
marked increase in serum triglyceride levels. $2 \mathrm{~h}$ after TNF treatment serum triglyceride levels were increased 2.4-fold and remained elevated for at least $17 \mathrm{~h}$ (increased 4.3-fold). Serum cholesterol levels were also increased at $17 \mathrm{~h}(34 \%)$. Thus, TNF administration to diabetic animals results in an increase in circulating lipid levels similar to those levels previously reported by this laboratory in nondiabetic animals, despite the absence of an effect on adipose tissue lipoprotein lipase activity.

In diabetic animals treatment with TNF increases hepatic lipid synthesis. The incorporation of tritiated water into fatty acids in the liver was increased 45\% 1-2 h after TNF, and $87 \%$ at $16-17 \mathrm{~h}$. In agreement with our previously reported observations, the incorporation of tritiated water into cholesterol in animals treated with TNF was significantly increased only after an extended period of time (increased 79\% at 16-17 h). At early time periods after TNF administration, cholesterol synthesis was not significantly different. The magnitude of the increase observed in hepatic lipid synthesis after TNF administration to diabetic animals is similar to that observed previously in normal animals.

These results indicate that TNF administration stimulates hepatic lipid synthesis in diabetic animals. Given the absence of a TNF effect on adipose tissue lipoprotein lipase activity in diabetic animals, the increase in circulating lipid levels after TNF administration is probably due to the TNF-induced stimulation of hepatic lipid synthesis in this experimental model. These results clearly indicate that, at least under these experimental conditions, the TNF-induced increase in circulating lipid levels can occur in the absence of a further inhibition of adipose tissue lipoprotein lipase activity.

Additional evidence that hepatic lipid synthesis may be of importance is our observation that lipoprotein clearance is not altered by TNF administration. In nondiabetic animals that were administered TNF, the clearance of triglyceride and cholesterol labeled chylomicrons from the circulation is almost identical to the clearance seen in normal animals $\left(t_{1 / 2}\right.$ triglyceride: control, $3.23 \pm 0.22 \mathrm{~min}, \mathrm{TNF}, 3.09 \pm 0.27 \mathrm{~min} ; t_{1 / 2}$ cholesterol: control, $5.66 \pm 0.43 \mathrm{~min}, \mathrm{TNF}, 5.50 \pm 0.35 \mathrm{~min})$. These results suggest that the increase in serum triglycerides after TNF administration is not due to a defect in the removal of triglyceride-rich lipoproteins from the circulation, and provide further support for our hypothesis that the increase in hepatic lipid synthesis contributes to the TNF-induced hyperlipidemia.

An additional important finding of the present study is that TNF administration to diabetic animals leads to elevated serum glucose levels. Serum glucose levels were increased $70 \%$ by $4 \mathrm{~h}$ after TNF administration and at $17 \mathrm{~h}$ glucose levels were increased $73 \%$ in the TNF-treated diabetic animals. In our streptozotocin-induced diabetic animals serum insulin levels were very low and did not change in response to TNF administration. Thus, the increased serum glucose levels in the TNF-treated diabetic animals are not due to a primary effect on insulin secretion and therefore must be due to alterations in glucose metabolism. The mechanism by which TNF alters glucose metabolism in streptozotocin-induced diabetic animals is currently under investigation. Additionally, the absence of an increase in serum insulin after TNF administration in these diabetic rats indicates that TNF stimulates de novo hepatic fatty acid synthesis by a mechanism independent of insulin.
In conclusion, the present study demonstrates that TNF administration to diabetic animals results in hyperlipidemia that is not the result of the inhibition of adipose tissue lipoprotein lipase activity by TNF. However, hepatic lipid synthesis is increased after TNF administration, suggesting that TNF-induced stimulation of hepatic lipid synthesis may account for the increase in serum lipid levels in diabetic animals. Our hypothesis is further supported by the observation that there is no decrease in the removal of chylomicrons, a triglyceride-rich lipoprotein, from the circulation of TNF-treated animals.

\section{Acknowledgments}

We thank Dr. John Patton and Dr. H. Michael Shepard of Genentech, Inc. and Dr. Marvin D. Siperstein for their continued interest in our work. We thank Jennifer A. Verdier for assistance with the graphics, Donald Ong for technical assistance, and Maggie Joe and Pam Herranz for the excellent editorial assistance.

This work was supported by grants from the Veterans Administration, the National Institutes of Health (AM-37102), and the University of California, University-wide Task Force on AIDS. Dr. Feingold and Dr. Grunfeld are the recipients of Clinical Investigator Awards from the Veterans Administration.

Note added in proof. We have recently demonstrated (32) that in normal rats, TNF induces an increase in serum triglycerides before the decrease is seen in lipoprotein lipase in epididymal fat pads (19), and that lipoprotein lipase in most other tissues is not decreased by TNF treatment in vivo (32).

\section{References}

1. Beisel, W. R. 1975. Metabolic response to infection. Annu. Rev. Med. 26:9-20.

2. Gallin, J. I., D. Kaye, and W. M. O'Leary. 1969. Serum lipids in infection. N. Engl. J. Med. 281:1081-1086.

3. Fiser, R. H., J. C. Denniston, and W. R. Beisel. 1972. Infection with diplococcus pneumoniae and salmonella typhimurium in monkeys: changes in plasma lipids and lipoproteins. J. Infect. Dis. 125:5460 .

4. Hirsch, R. L., D. G. McKay, R. I. Travers, and R. K. Skraly. 1964. Hyperlipidemia, fatty liver, and bromsulfophthalein retention in rabbits injected intravenously with bacterial endotoxins. J. Lipid Res. 5:563-568.

5. Lees, R. S., R. H. Fiser, Jr., W. R. Beisel, and P. J. Bartelloni. 1972. Effects of an experimental viral infection on plasma lipid and lipoprotein metabolism. Metab. Clin. Exp. 21:825-833.

6. Griffiths, J., A. C. Groves, and F. Y. T. Leung. 1972. The relationship of plasma catecholamines to serum triglycerides in canine gram-negative bacteremia. Surg. Gynecol. Obstet. 134:795-798.

7. Bagby, G. J., and J. A. Spitzer. 1980. Lipoprotein lipase activity in rat heart and adipose tissue during endotoxic shock. Am. J. Physiol. 238:H325-H330.

8. Kaufmann, R. L., C. F. Matson, A. H. Rowberg, and W. R. Beisel. 1976. Defective lipid disposal mechanisms during bacterial infections in rhesus monkeys. Metab. Clin. Exp. 25:615-624.

9. Kaufmann, R. L., C. F. Matson, and W. R. Beisel. 1976. Hypertriglyceridemia produced by endotoxin: role of impaired triglyceride disposal mechanisms. J. Infect. Dis. 133:548-555.

10. Guckian, J. C. 1973. Role of metabolism in pathogenesis of bacteremia due to diplococcus pneumoniae in rabbits. J. Infect. Dis. 127:1-8.

11. 1982. The interferon system: a review to 1982, parts I and II. Tex. Rep. Biol. Med. 41:1-715. 
12. 1983. Interleukins, lymphokines, and cytokines. Proc. Third Int. Lymphokine Workshop. 1-799.

13. Dinarello, C. A., and J. W. Mier. 1986. Interleukins. Annu. Rev. Med. 37:173-178.

14. Beutler, B., and A. Cerami. 1986. Cachectin and tumour necrosis factor as two sides of the same biological coin. Nature (Lond.). 320:584-588.

15. Feingold, K. R., and C. Grunfeld. 1987. Tumor necrosis factor-alpha stimulates hepatic lipogenesis in the rat in vivo. J. Clin. Invest. 80:184-190.

16. Pekala, P. H., M. Kawakami, C. W. Angus, M. D. Lane, and A. Cerami. 1983. Selective inhibition of synthesis of enzymes for de novo fatty acid biosynthesis by an endotoxin-induced mediator from exudate cells. Proc. Natl. Acad. Sci. USA. 80:2743-2747.

17. Kawakami, M., P. H. Pekala, M. D. Lane, and A. Cerami. 1982. Lipoprotein lipase suppression in 3T3-L1 cells by an endotoxininduced mediator from exudate cells. Proc. Natl. Acad. Sci. USA. 79:912-916.

18. Patton, J. S., H. M. Shepard, H. Wilking, G. Lewis, B. B. Aggarwal, T. E. Eessalu, L. A. Gavin, and C. Grunfeld. 1986. Interferons and tumor necrosis factors have similar catabolic effects on 3T3-L1 cells. Proc. Natl. Acad. Sci. USA. 83:8313-8317.

19. Semb, H., J. Peterson, J. Tavernier, and T. Olivecrona. 1987. Multiple effects of tumor necrosis factor on lipoprotein lipase in vivo. J. Biol. Chem. 262:8390-8394.

20. Kessler, J. I. 1963. Effect of diabetes and insulin on the activity of myocardial and adipose tissue lipoprotein lipase. J. Clin. Invest. 42:362-367.

21. Schnatz, J. D., and R. H. Williams. 1963. The effect of acute insulin deficiency in the rat on adipose tissue lipolytic activity and plasma lipids. Diabetes. 12:174-178.

22. Feingold, K. R., M. H. Wiley, G. MacRae, A. H. Moser, S. R. Lear, and M. D. Siperstein. 1982. The effect of diabetes mellitus on sterol synthesis in the intact rat. Diabetes. 31:388-395.
23. Pennica, D., G. E. Nedwin, J. S. Hayflick, P. H. Seeburg, R. Derynck, M. A. Palladino, W. J. Kohr, B. B. Aggarwal, and D. V. Goeddel. 1984. Human tumour necrosis factor: precursor structure, expression and homology to lymphotoxin. Nature (Lond.). 312:724729.

24. Patton, J. S., P. M. Peters, J. McCabe, D. Crase, S. Hansen, A. B. Chen, and D. Liggitt. 1987. Development of partial tolerance to the gastrointestinal effects of high doses of recombinant tumor necrosis factor-alpha in rodents. J. Clin. Invest. 80:1587-1596.

25. Feingold, K. R., M. H. Wiley, G. MacRae, S. R. Lear, G. Zsigmond, and M. D. Siperstein. 1983. De novo sterologenesis in the intact rat. Metab. Clin. Exp. 32:75-81.

26. Pykalisto, O. V., W. C. Vogel, and E. L. Bierman. 1974. The tissue distribution of triacylglycerol lipase, monacylglycerol lipase, and phospholipase in fed and fasted rats. Biochem. Biophys. Acta. 369:254-263.

27. Gavin, L. A., F. McMahon, and M. Moeller. 1985. Modulation of adipose lipoprotein lipase by thyroid hormone and diabetes. Diabetes. 34:1266-1271.

28. Young, N. L., C. D. Saudek, and S. A. Crawford. 1982. Total hydroxymethylglutaryl CoA reductase activity in the small intestine and liver of insulin deficient rats. J. Lipid Res. 23:266-275.

29. Goodman, D. S. The metabolism of chylomicron cholesterol ester in the rat. 1962. J. Clin. Invest. 41:1886-1896.

30. Nestel, P. J., R. J. Havel, and A. Bezman. 1963. Metabolism of constituent lipids of dog chylomicrons. J. Clin. Invest. 42:1313-1321.

31. Feingold, K. R., S. R. Lear, and J. M. Felts. 1987. The disappearance from the circulation of chylomicrons obtained from control and diabetic rats. Endocrinology. 121:475-480.

32. Grunfeld, C., R. Gulli, A. H. Moser, L. A. Gavin, and K. R. Feingold. The effect of tumor necrosis factor administration in vivo on lipoprotein lipase activity in various tissues of the rat. J. Lipid Res. In press. 